\title{
TÉCNICAS E INSTRUMENTOS PARA LA EVALUACIÓN DE LA COMUNICACIÓN ORAL: DISEÑO Y VALIDACIÓN
}

\author{
ASSESSMENT INSTRUMENTS AND TECHNIQUES FOR ORAL \\ COMMUNICATION: DESIGN AND VALIDATION
}

\author{
TÉCNICAS E INSTRUMENTOS PARA AVALIAÇÃO DE COMUNICAÇÃO \\ ORAL: PROJETO E VALIDAÇÃO
}

\author{
Alberto Corpas Martos \\ Consejería de Educación. Junta de Andalucía, España \\ https://orcid.org/0000-0001-8272-7622 \\ alberto@clasedelengua.com \\ Manuel Francisco Romero Oliva \\ Universidad de Cádiz, España \\ https://orcid.org/0000-0002-6854-0682 \\ manuelfrancisco.romero@uca.es
}

Recibido: 28/03/2021 Revisado:16/04/2021 Aceptado: 16/04/2021 Publicado: 20/04/2021

Resumen: La expresión y comprensión orales han sido tradicionalmente las destrezas comunicativas con más dificultades para ser enseñadas en la escuela. No obstante, se acepta que la comunicación oral es imprescindible en la formación y en la adquisición de las competencias clave para el aprendizaje permanente. Por ello, debemos aceptar que la palabra oral tiene que estar presente en el aula y formar parte del aprendizaje del estudiante de manera consciente, no meramente vehicular. Para conocer la realidad sobre la enseñanza de la oralidad debemos tener en cuenta al sistema, concretado en el centro educativo, al profesorado y al alumnado. En este estudio se proponen instrumentos y metodologías para la evaluación de la comunicación oral. Se incluye una perspectiva múltiple a partir de la observación del profesorado, la autoevaluación del alumnado y el análisis documental del centro en el que se enmarca el estudio para complementar el proceso de enseñanza-aprendizaje. Se trata de hacer confluir en la propuesta experiencias previas de pruebas estandarizadas y dotar de importancia al análisis cualitativo del contexto educativo dando voz al investigador y a los participantes.

Palabras claves: Educación; Comunicación; Tecnologías; Técnica; Instrumento.

Abstract: The oral expression and comprehension have been traditionally the communication skills with more problems to be teached at school. Nevertheless, is acceptable that the oral communication is imprescindible in the formation and in the adquisition of key competences for lifelong learning. Due to this, we have to accept that the oral word must be present at the classroom and take part in the student's learning in a conscient way, not only in a working language one. To know the reality of teaching oral communication it is necessary to consider the system, concreted in the educational center, the teaching staff and the learners. In this study, instruments and methodologies are proposed for the evaluation of oral communication. A multiple perspective is included from the observation by the teaching staff, the student's self-assessment and the documentary analysis of the center where the research is framed to complete the teachinglearning process. It is about bringing together in the proposal the previous experiences of standardized tests and giving importance to the qualitative analysis of the educational context, giving a voice to the researcher and participants.

Keywords: Education; Communication; Technologies; Technique; Instrument. 
Resumo: Expressão oral e compreensão têm sido tradicionalmente as habilidades de comunicação mais difíceis de serem ensinadas na escola. No entanto, admite-se que a comunicação oral é essencial na formação e na aquisição de competências essenciais para a aprendizagem ao longo da vida. Portanto, devemos aceitar que a palavra oral deve estar presente em sala de aula e fazer parte da aprendizagem do aluno de forma consciente, não meramente veicular. Para conhecer a realidade sobre o ensino da oralidade devemos levar em consideração o sistema, especificado no centro educacional, os professores e os alunos. Neste estudo são propostos instrumentos e metodologias para a avaliação da comunicação oral. Uma perspectiva múltipla é incluída a partir da observação dos professores, da autoavaliação dos alunos e da análise documental do centro em que o estudo se enquadra para complementar o processo de ensino-aprendizagem. Trata-se de reunir na proposta experiências prévias de testes padronizados e dar importância à análise qualitativa do contexto educacional, dando voz ao investigador e aos participantes.

Palavras-chave: Educação; Comunicação; Tecnologias; Técnica; Instrumento.

Cómo citar este artículo: Corpas, A., y Romero, M.F. (2021). Técnicas e instrumentos para la evaluación de la comunicación oral: diseño y validación. Hachetetepé. Revista científica en Educación y Comunicación, (22), 1-36. https://doi.org/10.25267/Hachetetepe.2021.i22.1205

\section{INTRODUCCIÓN}

A partir de nuestra experiencia, tanto como estudiantes o como docentes, percibiremos con cierta rapidez que la enseñanza de las destrezas orales ha sido frecuentemente relegada dentro del desarrollo de la competencia comunicativa, de manera general, y de la competencia lingüística, en particular, desde una concepción sistemática. Si las percepciones personales tienen un peso específico, estas se refuerzan con hechos incuestionables como la escasa presencia de la oralidad en los diseños curriculares y el desigual peso en las metodologías empleadas en el aula pues "la habilidad de la expresión oral ha sido siempre la gran olvidada de una clase centrada en la gramática y en la lectoescritura" (Cassany et al., 1994, p. 134) y, además:

Se tiende a considerar que la competencia oral, tanto en sus usos formales como en los informales, se adquiere y se desarrolla de forma natural sin que sea necesario enseñarla de forma sistemática, a diferencia de la lengua escrita que requiere un trabajo propiamente escolar (Cros y Vilà, 1996, p. 174).

$\mathrm{Si}$ aceptamos estas creencias, "no sería necesario que la escuela realizara ningún trabajo específico de lengua oral” (Del Río y Sánchez Cano, 1996, p. 3). Sin embargo, parece fácil detectar la dificultad -o incapacidad- que muestran para la comunicación oral, ya no solo los alumnos y alumnas de niveles preuniversitarios, sino aquellos que se encuentran inmersos en estudios superiores, o, yendo más allá, buena parte de la sociedad actual.

La palabra hablada ha de estar presente en el aula y permitir a los estudiantes practicar y reflexionar sobre su uso. La escuela debe garantizar el acceso al dominio de diferentes registros lingüísticos desde un punto de vista comunicativo y pragmático para garantizar el desarrollo competencial del alumnado. Nos parece relevante al respecto la aportación de Abascal et al. (1993, pp. 31-32):

El estudio de la lengua no tiene que hacerse sólo desde una de sus vertientes: la lengua escrita. Todos los miembros de una comunidad lingüística han sido, en primer lugar, hablantes (algunos serán exclusivamente hablantes toda su vida), y sólo como consecuencia del estudio, son hoy, además, lectores y escritores. Si a 
esto añadimos que la mayoría de las personas reciben y emiten más cantidad de información oral que escrita, no parece que haya ningún motivo para seguir observando el funcionamiento del sistema sólo en textos escritos. Dicho de otra forma, a pesar de las irregularidades de la lengua hablada, especialmente temidas por los lingüistas que trabajan desde la abstracción del hablante ideal, es perfectamente posible, y rentable para aumentar la competencia, hacer una reflexión sistemática sobre el código lingüístico también a partir de las realizaciones orales (pp.31-32).

Al realizar un diagnóstico sobre los motivos alegados por el profesorado para la ausencia del trabajo de la oralidad en la cotidianidad del aula aun con las sucesivas reformas educativas, a pesar de su variedad, aparecen lugares comunes sobre los males de la educación: ausencia de referencia en la formación escolar de los docentes, dificultades para evaluar una práctica compleja, la falta de metodología de aula que fomente la interacción debido a un excesivo número de estudiantes, el apego a prácticas pedagógicas basadas en la comprensión y composición escritas, las deficiencias en la formación inicial y permanente del profesorado, etc. (Corpas, 2019).

Frente a esto, debemos capacitar a nuestro alumnado para interactuar con un mundo donde la inmediatez y el multimedia han copado los intercambios sociales y culturales. Para poder interactuar como prosumidores -productores y consumidoresToffler (1979) en dicho contexto es necesario un dominio flexible de la comprensión y expresión orales. Es, por tanto, corresponsabilidad del docente acercar a los jóvenes a las capacidades para relacionarse con eficacia con estos mensajes, así como dotarles de capacidad de análisis y crítica que formen una ciudadanía activa y preparada para descifrar y contribuir al contexto en el que viven.

En el planteamiento inicial surge, por tanto, la necesidad de valorar los diferentes contextos social, académico y personal en el que se desenvuelven los participantes en la investigación. Solo a partir de un diagnóstico del punto de partida podremos trabajar significativamente sobre lo que ya saben como seres socializados que hablan y sus niveles potenciales de desarrollo. Pensamos que las destrezas relacionadas con la competencia comunicativa oral, como en cualquier otra destreza surgen de la práctica y la experiencia: “a hablar se aprende hablando". Para ello como reconoce Reyzábal (2001, p. 28):

Es necesario que la enseñanza se interese por la lengua que posee el niño (o el adulto) en la comunicación cotidiana, con todas sus imperfecciones e inexactitudes, pero que es la base de la que hay que partir. Digamos que es lo lingüísticamente dado y que permite el desarrollo posterior en cuanto que es la condición que posibilita ir de lo sencillo a lo complejo, de lo fácil a lo difícil, de lo conocido a lo desconocido, de lo concreto a lo abstracto, de lo particular a lo general...

Es ahí donde se evidencia el requerimiento de elaborar un marco de análisis de la competencia en comunicación oral desde su sistematización. Somos conscientes de esta competencia suele reducirse a la comprensión lectora, caso de las pruebas PISA. Por ello, no podemos obtener una visión de la situación real actualizada de los diferentes grados de adquisición de las destrezas orales en nuestro entorno. Podríamos tomar como base la comunidad autónoma de Andalucía (España) y recurrir a las Pruebas de Evaluación de Diagnóstico (PED) que se realizaron en los centros andaluces en los cursos comprendidos entre el 2006/2007 y el 2011/2012. Sin embargo, aunque en ellas se evaluaron los niveles de competencia en comunicación lingüística - comprensión oral, comprensión lectora y

e-ISSN:2172-7910

Doi:10.25267/Hachetetepe.2021.i22.1205

Universidad de Cádiz 
expresión escrita - se mantiene un predominio de los aspectos de la escritura frente a la oralidad en donde la expresión oral es, directamente, obviada como una de las dimensiones en el diseño de la prueba. Tras lo observado, consideramos necesario ampliar el foco de actuación y proponer un modelo de evaluación de la comunicación oral en su amplio desempeño: no solo las habilidades receptivas, como la comprensión oral; sino también la productivas, como la expresión oral.

\section{METODOLOGÍA}

La metodología desarrollada para el diseño y validación de las técnicas e instrumentos para la evaluación de la comunicación oral obedece a Fox (1981).

En este sentido, se llevaron a cabo los siguientes pasos:

1. Limitar el cuestionario para que los sujetos puedan desarrollarlo.

2. Estructurar el modelo de las respuestas para que los sujetos reduzcan su escrito.

3. Especificar los objetivos y la estructura del cuestionario para que puedan contestar sin ningún problema

4. Utilizar un sistema para que puedan ver los resultados de ello.

La validación de las técnicas e instrumentos se justifica tomando como referencia a McMillan y Schumacher (2005) - Tabla 1—:

Tabla 1

Fases de la elaboración y validación de técnicas e instrumentos

\begin{tabular}{|c|c|c|}
\hline Fase & Momentos & Concreción en la investigación \\
\hline 1 & Justificación & $\begin{array}{l}\text { Análisis de la literatura de referencia y estado de la } \\
\text { cuestión }\end{array}$ \\
\hline 2 & Delimitación de objetivos & Delimitación de objetivos y dimensiones de estudio. \\
\hline 3 & Descripción de ítems & $\begin{array}{l}\text { Desarrollo de enunciados efectivos, según los criterios } \\
\text { de Babbie (2001), para integrar los objetivos de estudio } \\
\text { y evitar posibles dificultades de interpretación en su } \\
\text { aplicación. }\end{array}$ \\
\hline 4 & Revisión de ítems & Consulta a expertos del área \\
\hline 5 & Constructo del formulario & $\begin{array}{l}\text { Elaboración de instrumentos y distribución de ítems } \\
\text { por dimensiones de estudio }\end{array}$ \\
\hline 6 & Pretest & $\begin{array}{l}\text { Realización de una prueba de control y verificación en } \\
\text { un centro educativo. }\end{array}$ \\
\hline 7 & Revisión & $\begin{array}{l}\text { Las aportaciones de expertos y pretests sirvieron para } \\
\text { la revisión final de los cuestionarios que aparecen en } \\
\text { este estudio. }\end{array}$ \\
\hline
\end{tabular}

Fuente: McMillan y Schumacher (2005).

\subsection{Técnicas e instrumentos de recogida de información}

Las técnicas e instrumentos para el diagnóstico de la competencia comunicativa oral se corresponden con la investigación por encuesta que describe Torrado (2004): el 
cuestionario y la entrevista, términos que en muchas ocasiones aparecen como sinónimos. En nuestro caso, distinguiremos ambos instrumentos, principalmente, por la mediación de las tecnologías en el caso del primero y el encuentro cara a cara en el segundo. Atendiendo al propio diseño, entendemos el cuestionario como un repertorio cerrado y planificado de preguntas, mientras que en el caso de la entrevista optamos por las semiestructuradas, que se encuentran "indefinidas en menor o mayor grado" (Torrado, 2004, p. 240).

La elección de la naturaleza de las preguntas de los cuestionarios desde una perspectiva amplia, incluyendo abiertas, cerradas, escalas de valoración, etc. trata de fundamentar la elección de un paradigma mixto de investigación. Si las encuestas pertenecen por definición al enfoque cuantitativo, no conviene olvidar que estamos analizando una realidad de la que el investigador ya forma parte y, por lo tanto, la elección de la muestra y la selección de las cuestiones se ve muy condicionada. En este sentido, el paradigma cualitativo se ve reflejado en propuestas como la Del Rincón (1997) que incluye como característica cualitativa el hecho de que la realidad educativa es analizada por el investigador que comparte el mismo marco de referencia que los participantes, alejándose así del observador externo más vinculado a lo cuantitativo.

Cabe reseñar que la obtención de datos a partir del cuestionario destinado a la autoevaluación del alumnado de sus propias destrezas orales, se ve complementada por una prueba de evaluación inicial. Los axiomas en los que se basa su elaboración fueron los siguientes:

- Integración de destrezas lingüísticas, que están imbricadas en los actos comunicativos y los usuarios no tienden a su separación artificial.

- Comprensión directa e inferencia, de forma que haya respuestas que se puedan extraer directamente de la audición, como los rasgos dialectales, pero que también sea preciso comprender y analizar el mensaje en profundidad para activar el repertorio de conocimientos previos y de experiencias comunicativas del alumnado.

- Brevedad, para evitar las resistencias propias del alumnado a la realización de pruebas al inicio del curso escolar que después influyen testimonialmente en el diseño de las programaciones o en su evaluación.

- Inclusión de producción verbal en el aula y fuera de ella gracias a la mediación de las tecnologías.

\subsubsection{Validación y triangulación de informaciones}

Nos detenemos en los conceptos de validez y fiabilidad, los cuales reconocemos como dos cualidades esenciales que deben poseer las investigaciones científicas: "Si el instrumento o instrumentos reúnen estos requisitos habrá cierta garantía de los resultados obtenidos en un determinado estudio y, por tanto, las conclusiones pueden ser creíbles y merecedoras de una mayor confianza" (Pérez Serrano, 1994, p. 71).

Ambos términos quedan definidos por Angrosino (2012, p. 86), de modo que "la fiabilidad es una medida del grado en que una observación dada es coherente con un patrón general y no el resultado de una oportunidad aleatoria. La validez es la medida del grado en que una observación demuestra realmente lo que parece demostrar".

Como defiende Rubio (2017, p. 187) "El problema asociado a las investigaciones cualitativas es que se les aplica cánones de la investigación cuantitativa para determinar 
su validez y fiabilidad, cuando existen mecanismos que permiten alcanzar un grado aceptable de ambas".

Precisamente, apoyándonos en las premisas defendidas por Rubio (2017), alcanzamos los términos clave de credibilidad y transferibilidad de los resultados, que, a nuestro juicio, resultan claves para alcanzar la validez en la investigación educativa de corte cualitativo y evitar de esta manera el reduccionismo a circunstancias y entornos tan concretos que resulten imposibles de extrapolar.

Para alcanzar los niveles óptimos de validez, nos apoyamos en los trabajos de McMillan y Schumacher (2005, p. 415) que establecen diez estrategias posibles que deben abordarse desde la investigación. En la siguiente tabla describimos las distintas estrategias y su uso en la presente investigación - Tabla 2-:

Tabla 2

Estrategias para alcanzar niveles óptimos de validez en la investigación

\begin{tabular}{|c|c|c|}
\hline Estrategia & Descripción & Uso \\
\hline $\begin{array}{l}\text { Campo de trabajo } \\
\text { prolongado y continuo }\end{array}$ & $\begin{array}{l}\text { Posibilita que los datos sean analizados y corroborados, } \\
\text { asegurando la concordancia entre información y realidad }\end{array}$ & SÍ \\
\hline $\begin{array}{l}\text { Estrategia con varios } \\
\text { métodos }\end{array}$ & $\begin{array}{l}\text { Permite la triangulación en la recopilación y análisis de los } \\
\text { datos }\end{array}$ & SÍ \\
\hline $\begin{array}{l}\text { Lenguaje del } \\
\text { participante; recuentos de } \\
\text { repeticiones }\end{array}$ & $\begin{array}{l}\text { Obtiene, principalmente a través de entrevistas, testimonios } \\
\text { de los participantes y citas de los documentos }\end{array}$ & SÍ \\
\hline $\begin{array}{l}\text { Indicadores de baja } \\
\text { inferencia }\end{array}$ & $\begin{array}{l}\text { Registra descripciones detalladas y casi literales de } \\
\text { personas, lugares y situaciones }\end{array}$ & SÍ \\
\hline Investigadores múltiples & $\begin{array}{l}\text { Un equipo de investigación recoge datos para estimar su } \\
\text { correspondencia }\end{array}$ & NO \\
\hline $\begin{array}{l}\text { Datos registrados de } \\
\text { manera mecánica }\end{array}$ & A través de fotografías, grabaciones de audio o vídeo, etc. & SÍ \\
\hline Investigador participante & $\begin{array}{l}\text { Uso de diarios anecdotarios donde los participantes reflejan } \\
\text { sus impresiones }\end{array}$ & SÍ \\
\hline $\begin{array}{l}\text { Comprobación de } \\
\text { miembros }\end{array}$ & $\begin{array}{l}\text { Comprobación informal con los participantes para precisar } \\
\text { durante la recopilación de datos }\end{array}$ & SÍ \\
\hline Revisión de participantes & $\begin{array}{l}\text { Pregunta a cada uno de los participantes para revisar los } \\
\text { resúmenes de las entrevistas realizadas }\end{array}$ & SÍ \\
\hline $\begin{array}{l}\text { Casos negativos o datos } \\
\text { discrepantes }\end{array}$ & $\begin{array}{l}\text { Búsqueda activa de casos negativos para registrarlos y } \\
\text { analizarlos }\end{array}$ & SÍ \\
\hline
\end{tabular}

Fuente: McMillan y Schumacher (2005). 


\subsubsection{Cuestionarios}

En primer lugar, diferenciaremos entre dos tipos diferentes de validez:

- De contenido, que mediría el grado en que el cuestionario refleja un dominio específico de contenido de lo que se mide.

- De criterio, que se establece al validar el instrumento de medición al compararlo con algún criterio externo que pretenda medir lo mismo.

En el caso de la validez de contenido, hemos categorizado el cuestionario en una serie de dimensiones y subdimensiones que permiten clasificar las respuestas de los informantes.

Para la validez de criterio, trazamos comparaciones con otros estudios y con los ítems evaluados en algunas acreditaciones institucionalizadas, de forma que acotamos la discrecionalidad en el diseño del cuestionario.

Todos los cuestionarios han seguido un ciclo de revisión partiendo de la propuesta del investigador, la revisión de expertos de diferentes ámbitos educativos especialistas y no especialistas en los temas tratados y una última fase de ensayo con una muestra seleccionada para contrastar la visión del informante y las dificultades encontradas.

Una vez analizada la bibliografía y superado un periodo de reflexión, se llegó a la conclusión de que la mejor opción pasaba por la creación de los siguientes cuestionarios:

1. Cuestionario sobre las destrezas de la comunicación oral del alumnado para el profesorado (DCOP).

2. Cuestionario de autoevaluación sobre las destrezas de la comunicación oral del alumnado (DCOA).

3. Lista de comprobación para el análisis documental sobre el fomento de la Competencia Comunicativa Oral del centro.

\section{RESULTADOS}

\subsection{Cuestionario 'Destrezas de la comunicación oral del alumnado para el} profesorado (DCOP) ${ }^{1}$

Tratamos de profundizar en las creencias del profesorado acerca del desarrollo de la competencia comunicativa oral de su alumnado, así como en las prácticas más frecuentes en el aula.

Los ítems están agrupados en las siguientes dimensiones y subdimensiones:

Tabla 3

Validez del cuestionario DCOP

\begin{tabular}{|c|c|}
\hline \multicolumn{2}{|c|}{ D1. DIMENSIÓN PERSONAL } \\
\hline SUBDIMENSIÓN & ÍTEMS \\
\hline D1.1 Datos personales & $1.1 .1,1.1 .2$ \\
\hline D1.2 Datos laborales & $1.2 .1,1.2 .2,1.2 .3,1.2 .4,1.2 .5$ \\
\hline D1.3 Datos académicos & $1.3 .1,1.3 .2,1.3 .3,1.3 .4,1.3 .5,1.3 .6$ \\
\hline D1.4 Formación continua & $1.4 .1,1.4 .2$ \\
\hline $\begin{array}{l}\text { D1.5 Experiencias de aula } \\
\text { D2. DI }\end{array}$ & $\begin{array}{l}\text { 1.5.1, } 2.10,2.11 \\
\text { NSTRUMENTAL }\end{array}$ \\
\hline
\end{tabular}


D2.1 Visión propia

D2.2 Visión global y de centro
$2.2,2.3,2.9$

$2.4,2.12,2.13,2.14,2.15,2.16,2.17,2.18$

D3. DIMENSION EVALUATIVA

\begin{tabular}{ll}
\hline D3.1 Tratamiento de la oralidad en el aula & $2.1,2,5,2,6,2.7,2.8$ \\
& $3.1 .1,3.1 .2,3.1 .3,3.1 .4,3.1 .5,3.1 .6,3.1 .7$, \\
D3.2 Hablar & $3.1 .8,3.1 .9,3.1 .10$ \\
& $3.2 .1,3.2 .2,3.2 .3,3.2 .4,3.2 .5,3.2 .6$ \\
D3.3 Escuchar & $3.3 .1,3.3 .2,3.3 .3,3.3 .4,3.3 .5,3.3 .6,3.3 .7$, \\
& $3.3 .8,3.3 .9$ \\
D3.4 Habilidades en la exposición & $3.4 .1,3.4 .2,3.4 .3$
\end{tabular}

Fuente: Elaboración propia

A partir de este cuestionario - Anexo 1- perseguimos conocer el perfil profesional de los docentes informantes. Analizamos la influencia del área de conocimiento y las lenguas vehiculares utilizadas en la docencia, así como el impacto de las formaciones inicial y continua. Como valor añadido, se detectan nuevas necesidades formativas que puedan verse reflejadas en el Plan de Formación que el centro comparte con el Centro de Profesorado de referencia.

Al sondear acerca de las buenas prácticas relevantes relacionadas con la oralidad, se busca conocer las dificultades y resistencias, además de la contribución de las programaciones didácticas. En este último aspecto, se destacan la evaluación del profesorado de las microdestrezas que componen la competencia comunicativa oral (Cassany et al., 1994; Reyzábal, 2001; Galera y Molina, 2016), además de las capacidades del alumnado para la autoevaluación y coevaluación.

\subsection{Cuestionario 'Autoevaluación sobre las destrezas de la comunicación oral del alumnado (DCOA) ${ }^{2}$}

Analizamos la capacidad del alumnado para su autoevaluación y conocimiento de las propias prácticas relacionadas con la competencia comunicativa oral tanto en los ámbitos de la vida cotidiana como en la vida académica. secciones:

Las preguntas del cuestionario -Anexo 2 - se encuentran agrupadas en cuatro

1. Perfil

2. La comunicación en el día a día

3. La comunicación en el instituto con el profesor y en las actividades de clase

4. Práctica de la comunicación oral en el ámbito académico

A su vez, cada uno de los apartados presenta subsecciones que clasifican las distintas variables estudiadas. 
Tabla 4

Validez del cuestionario DCOA

\section{D1. DIMENSIÓN PERSONAL}

\section{SUBDIMENSIÓN}

D1.1 Datos personales

D1.2 Datos académicos
$1.1 .1,1.1 .2$

$1.2 .1,1.2 .2,1.2 .3,1.2 .4,1.2 .5,1.2 .6$

\section{ÍTEMS}

\section{D2. DIMENSIÓN INSTRUMENTAL}

D2.1 Práctica de la comunicación oral en el 4.1, 4.2, 4.3

ámbito académico

\section{D3. DIMENSION EVALUATIVA}

D3.1 Hablar e interactuar en el día a día

2.1.1, 2.1.2, 2.1.3, 2.1.4, 2.1.5, 2.1.6, 2.1.7,

2.1.8, 2.1.9, 2.1.10, 2.1.11

D3.2 Escuchar en el día a día

$2.2 .1,2.2 .2,2.2 .3,2.2 .4,2.2 .5$

D3.3 Hablar e interactuar en la vida académica

3.1.1, 3.1.2, 3.1.3, 3.1.4, 3.1.5, 3.1.6, 3.1.7, $3.1 .8,3.1 .9,3.1 .10$

D3.4 Escuchar en la vida académica

3.2.1, 3.2.2, 3.2.3, 3.2.4, 3.2.5, 3.2.6

D3.5 Habilidades en la exposición

3.3.1, 3.3.2, 3.3.3, 3.3.4, 3.3.5, 3.3.6, 3.3.7, 3.3.8, 3.3.9

D3.6 Capacidades de autoevaluación

3.4.1, 3.4.2, 3.4.3

D3.7 Percepciones sobre la autoevaluación

$4.4,4.5,4.6$

Fuente: Elaboración propia

En este caso, pretendemos caracterizar el perfil personal del informante y la posible influencia de su trayectoria académica en su desarrollo competencial. Del mismo modo, también pretendemos averiguar la capacidad de detectar expresamente prácticas relacionadas con la oralidad, así como identificar sus propias dificultades y resistencias. Dentro de la dimensión evaluativa intentamos valorar la autoevaluación del alumnado de sus propias capacidades a partir de la apreciación de sus microdestrezas (Coll y Solé, 2001; Ramírez Martínez, 2002; Hernando et al., 2011).

\subsection{Lista de comprobación para el análisis documental sobre el fomento de la} Competencia Comunicativa Oral a nivel de centro ${ }^{3}$

En este caso ha sido más difícil encontrar una guía que pudiera servir como pauta para la elaboración de la evaluación. A pesar de que la Agencia Andaluza de Evaluación Educativa (AGAEVE) realizó un Estudio sobre la detección de buenas prácticas educativas: Desarrollo de la competencia en comunicación lingüística, los indicadores reflejados están vinculados a las calificaciones y a las evaluaciones externas realizadas mediante las pruebas de diagnóstico de los años 2010 a 2012, aunque extrayendo conclusiones centradas principalmente en la lectoescritura. De igual modo, La Consejería de Educación puso en marcha en el curso 2013-2014 una serie de programas educativos 
vinculados al ámbito de la comunicación lingüística, destinados a la mejora de esta competencia clave. La AGAEVE, durante el curso 2014-2015, desarrolló un estudio denominado Detección y difusión de buenas prácticas educativas en centros que desarrollan programas del ámbito de la comunicación lingüística, a partir del cual completamos los indicadores prescriptivos definidos por la legislación, así como otros de elaboración propia.

Como modelo de referencia en el análisis de aspectos organizativos de los centros educativos vinculados al aprendizaje del alumnado, nos basamos en la estructura propuesta por Heredia y Moreno Verdulla (2015). Dichos autores proponen una lista de comprobación de todos los aspectos relacionados incluyendo la posibilidad de añadir observaciones cualitativas que permitan la obtención de evidencias o de propuestas de mejora.

Proponemos una lista de comprobación para el análisis documental sobre el fomento de la Competencia Comunicativa Oral del centro educativo -Anexo 3-. A partir de ahí, analizamos:

- Participación en Planes y Programas. Los posteriormente llamados por la propia administración "Programas para la innovación educativa" son concebidos como herramientas de innovación que favorezcan un cambio educativo, con la incorporación de metodologías activas y participativas, apostando por nuevas formas de trabajo y de organización. Se describen como respuesta para estimular al alumnado y al profesorado la necesidad de formación y adaptación a las nuevas exigencias sociales. Una forma de hacer las cosas, que parte siempre del autoconocimiento de los propios individuos, genera un espacio de reflexión, fomenta el trabajo en equipo, la comunicación y la escucha e impulsa a la acción, a través de la creatividad, la iniciativa, el cálculo de los riesgos y la asunción del fracaso en el proceso. Son, en definitiva, proyectos de trabajo abiertos que ofrecen un marco de actuaciones susceptible de desarrollarse a lo largo del tiempo de diversas formas.

- Dinámicas de trabajo y elaboración de materiales. Analizamos aquí la coordinación prevista en el centro en busca de la transdisciplinariedad y transversalidad del trabajo, que debe ser adecuado a las diferentes edades y niveles. Observamos si el centro favorece la dinámica de trabajo colaborativo entre el profesorado para la realización de actividades o recursos y materiales innovadores. Desde el punto de vista del alumnado se busca el planteamiento de tareas integradas o proyectos de investigación para el desarrollo de su competencia comunicativa.

- Formación del profesorado. Siendo una de las debilidades habituales el desarrollo de la competencia comunicativa del alumnado analizamos si el Plan de Formación del centro tiene un programa específico de formación en competencia comunicativa. Desde un punto de vista biográfico, nos interesamos también por la percepción del profesorado y su preocupación por actualizar su formación a este respecto.

- Estrategias de enseñanza-aprendizaje. Buscamos la explicitación de la contribución al desarrollo de la competencia en comunicación lingüística en las programaciones didácticas de las diferentes áreas de conocimiento, así como la concreción sobre las destrezas vinculadas a la oralidad. Del mismo modo, se sondea la presencia de procedimientos de evaluación y criterios de calificación 
para valorar el grado de adquisición de la competencia en comunicación lingüística por parte del alumnado.

- Evidencias en el Plan de Centro. Es una dimensión más abierta con un diagnóstico flexible acerca de las apuestas concretas del proyecto educativo relacionadas con el aprendizaje y análisis crítico mediante la comprensión y expresión orales. Se analiza también el establecimiento de cauces que favorezcan la comunicación entre los distintos sectores de la comunidad educativa.

Desde la desaparición de la AGAEVE en 2019, las competencias relativas a la evaluación del sistema educativo han recaído en la Dirección General de Ordenación Educativa para integrar dicho proceso en la política educativa. En cualquier caso, desde el trasvase de competencias no ha habido nuevos estudios ni información sobre el desarrollo de la competencia en comunicación lingüística en los centros andaluces a excepción de las pruebas homologadas ESCALA, que como es sabido, aportan información sobre la lectoescritura y cálculo, obviando una vez más a la oralidad. De ahí la necesidad de aportar enfoques externos e independientes para tratar de avanzar en este sentido y completar el análisis meramente cuantitativo realizado en la actualidad mediante los indicadores homologados de los centros educativos.

\section{CONCLUSIONES}

En definitiva, como ya hemos comentado desde el inicio de esta investigación, partimos de la constatación de cómo las destrezas relacionadas con la comprensión, expresión e interacción orales ocupan un segundo plano en la instrucción escolar. Esto queda explicitado en la omisión de dichas habilidades en las pruebas de diagnóstico y evaluación homologadas, tanto a nivel autonómico (ESCALA), como nacional o internacional (PISA). Todo esto nos lleva a la necesidad de proponer instrumentos que nos permitan medir y tomar decisiones sobre la potencial contribución al desarrollo de la competencia comunicativa oral del alumnado, ya que "necesitamos comprender la realidad, adentrarnos en ella, y eso solo es posible desde la investigación y el análisis" (Romero y Heredia, 2019, p. 52).

En este sentido, tal como indica Abascal (1993), aceptamos que debemos trabajar desde la realidad del estudiante y abrazar, incluso, la imperfección de la lengua hablada. Si partimos del hablante ideal descrito por la gramática, nuestro impacto sobre el desarrollo competencial y el aprendizaje del alumnado será más limitado. Proponemos en este sentido la necesidad de emerger las visiones del profesorado, así como dotar a los estudiantes de una capacidad de autoevaluación y análisis de sus propias producciones para detectar sus áreas de mejora, que tendrán un carácter único y personal.

Cobra entonces especial sentido conocer tanto las creencias del profesorado y sus experiencias en el tratamiento transversal del aprendizaje de la competencia comunicativa oral como sus dudas y resistencias. Es por ello que nuestro diagnóstico debe ser cualitativo - e incluso empático - para poder amoldar la respuesta y la propuesta a la situación de partida dentro del campo de la investigación.

No podemos olvidar, como indican Romero et al. (2020) que cualquier investigación que pretenda abarcar este objeto de estudio requiere una perspectiva amplia que busque describir y analizar las conductas sociales colectivas e individuales y ello conlleva compaginar varios métodos y técnicas de investigación a partir de las desarrolladas en este estudio. Es el caso de las entrevistas o los grupos focales. De hecho, queda de manifiesto el interés por el modelo desarrollado por Elliott (1990, pp. 25-26)

e-ISSN:2172-7910

Doi:10.25267/Hachetetepe.2021.i22.1205

Universidad de Cádiz 
que afirma relacionarse "con los problemas cotidianos experimentados por los profesores, en vez de los problemas teóricos definidos por los investigadores puros". Desde esta postura de seguimiento, "«lo que ocurre» se hace inteligible al relacionarlo con los significados subjetivos que los participantes les adscriben”. Es precisamente en este punto donde las entrevistas y la observación participante son herramientas necesarias. La presencia de la perspectiva narrativo-biográfica en la investigación justifica el uso de la entrevista que Flick (2012) considera como su base metodológica. Dada la fase de la investigación en la que se utilizan estos instrumentos, existen materiales y datos que permiten contrastar la veracidad y adecuación de las respuestas que se derivan de esta herramienta que concebimos como un hecho integrado dentro del contexto de un grupo focal o de discusión donde establecer conversaciones abiertas a partir de cuestionarios semiestructurados.

A partir de ese punto surge la posibilidad de realizar propuestas que venzan esas resistencias como el excesivo ruido en el aula, la dificultad de atender y retroalimentar a alumnado tan numeroso y diverso, o la falta de metodologías eficaces que permitan el registro y revisión de las producciones orales. Es por ello que apostamos en el marco de una investigación más amplia por la propuesta del uso de los Entornos Virtuales de Aprendizaje para, de esta manera, expandir los límites espaciotemporales del aula (Corpas y Rubio, 2017) y vencer así las dificultades anteriormente expuestas.

Se nos abren prospectivamente innumerables rutas para recorrer un camino mucho menos frecuentado que aquellos orientados a la lectoescritura. En el contexto andaluz, tenemos la posibilidad de explotar las potencialidades de los Programas de Innovación Educativa para el desarrollo de la competencia en comunicación lingüística - Proyecto Lingüístico de Centro (PLC) y ComunicA - en la inclusión del trabajo tanto desde las áreas lingüísticas como las no lingüísticas. Esto es posible desde la concepción vehicular y comunicativa de la lengua como eje transversal. El PLC se erige, además, como garante de la inclusión y equidad (Trujillo y Rubio, 2014) al integrarse en un Proyecto Educativo de Centro dando una respuesta sistémica a las necesidades comunicativas del alumnado $\mathrm{y}$ atender a procesos de atención a la diversidad.

\section{NOTAS}

${ }^{1}$ Enlace al cuestionario DCOP:

https://drive.google.com/file/d/0ByZJCuv490e4VGZEYUgxMTFJMEU/view

2. Enlace al cuestionario DCOA:

https://drive.google.com/file/d/0ByZJCuv490e4YTJReUo4NX1MQ0U/

${ }^{3}$ Enlace a tabla Evaluación del fomento de la competencia comunicativa oral: https://drive.google.com/file/d/1suw7wNiqTpSSmH8M5-qGgwGHY7UQNU62

\section{REFERENCIAS BIBLIOGRÁFICAS}

Abascal, M. D., Beneito, J. M., y Valero, F. (1993). Hablar y escuchar: una propuesta para la expresión oral en la enseñanza secundaria. Octaedro.

Agencia Andaluza de Evaluación Educativa (2007). Evaluación de Diagnóstico. Informe de Resultados. 2006-2007. Consejería de Educación. https://bit.ly/3n10R3H

Agencia Andaluza de Evaluación Educativa (2008). Evaluación de Diagnóstico. Informe de Resultados. 2007-2008. Consejería de Educación. https://bit.ly/3tAYhUm 
Agencia Andaluza de Evaluación Educativa (2009). Evaluación de Diagnóstico. Informe de Resultados. Andalucía 2008-2009. Consejería de Educación. https://bit.ly/3aqEEXx

Agencia Andaluza de Evaluación Educativa (2010). Evaluación de Diagnóstico. Informe de Resultados. Andalucía 2009-2010. Consejería de Educación. https://bit.ly/32u66zp

Agencia Andaluza de Evaluación Educativa (2011). Evaluación de Diagnóstico. Informe de Resultados. Andalucía 2010-2011. Consejería de Educación. https://bit.ly/3gpRKsa

Agencia Andaluza de Evaluación Educativa (2012). Evaluación de Diagnóstico. Informe de Resultados. Andalucía 2011-2012. Consejería de Educación. https://bit.ly/3efT663

Agencia Andaluza de Evaluación Educativa (2015). Estudio sobre la detección de buenas prácticas educativas: Desarrollo de la competencia en comunicación lingüística. Consejería de Educación. https://bit.ly/3gnqVET

Agencia Andaluza de Evaluación Educativa (2016). Estudio sobre buenas prácticas en Programas de Comunicación Lingüística. Consejería de Educación. https://bit.ly/3dysX2Z

Angrosino, M. (2012). Etnografía y observación participante en investigación cualitativa. Ediciones Morata.

Babbie, E. R. (2001). The practice of social research. CA Wadsworth/Thomsom Learning.

Cassany, D., Luna, M., y Sanz, G. (1994). Enseñar lengua. Graó.

Coll, C., y Solé, E. (2001). Enseñar y aprender en el contexto del aula. En C. Coll, J. Palacios y Á. Marchesi (Eds.), Desarrollo psicológico y educación, 2. Psicología de la educación escolar (pp. 357-386). Alianza.

Corpas, A., y Rubio, R. (2017). Expandiendo el aula a través del microblogging. Revista de Estudios Socioeducativos. ReSed, 5, 119-129. http://doi.org/10.25267/Rev_estud_socioeducativos.2017.i5.11

Corpas, A. (2019). Desarrollo de la Competencia Comunicativa Oral a través de los Entornos Virtuales de Aprendizaje [Tesis doctoral]. Universidad de Cádiz.

Cros, A., y Vilá, M. (1996). La lengua oral en la enseñanza secundaria: propuestas didácticas. En D. Cassany, E. Martos, E. Sánchez, T. Colomer, A. Cros y M. Vilá, Aspectos Didácticos de Lengua y Literatura, 8. Universidad de Zaragoza

Del Rincón, D. (1997). Investigación acción-cooperativa. En M. J. Gregorio, Memorias del seminario de investigación en la escuela. (pp.71-97). Santa Fe de Bogotá.

Del Río, M. J., y Sánchez Cano, M. (1996). Enseñar lengua oral en la escuela. En J. Escoriza, A. Barca, J. González y R. González (Eds.), Psicopedagogía de la instrucción (pp. 1-24). EUB.

Elliott, J. (1990). La investigación-acción en educación. Ediciones Morata.

Flick, U. (2012) Introducción a la investigación cualitativa. Ediciones Morata.

Fox, D. J. (1981). El proceso de investigación en educación. EUNSA.

Galera, M. V., y Molina, M. M. (2016). La escucha activa. En A. E. Díez, V. Brotons, D. Escandell y D. Rovira (Coords.), Aprendizajes plurilingües y literarios: Nuevos enfoques didácticos (pp.467-477). Publicaciones de la Universitat d'Alacant.

Heredia, H., y Moreno Verdulla, P. (2015). El plan de Lenguas y Biblioteca de centro, un análisis de las necesidades. En N. Ibarra, J. Ballester, M. ${ }^{a}$ L. Carrió y M. Romero 
(Coords.), Retos en la adquisición de las literaturas y de las lenguas en la era digital (pp.323-329). Universitat Politècnica de València.

Hernando, Á., Aguaded, J. I. y Pérez Rodríguez, M. A. (2011) .Técnicas de comunicación creativas en el aula: escucha activa, el arte de la pregunta, la gestión de los silencios. Educación y Futuro: Revista de investigación aplicada y experiencias educativas, (24), 153-180.

McMillan, J. H., y Schumacher, S. (2005). Investigación educativa. Una introducción conceptual. Pearson Educación.

Pérez Serrano, G. (1994). Investigación cualitativa. Retos e interrogantes II. Técnicas y análisis de datos. Editorial La Muralla.

Ramírez Martínez, J. (2002). La expresión oral. Contextos educativos: Revista de educación, (5), 57-72.

Reyzábal, M. V. (2001). La comunicación oral y su didáctica. Editorial La Muralla.

Romero, M. y Heredia, H. (2019). Técnicas para la evaluación de la lectura y las TIC: tres cuestionarios para su diagnóstico. Campo Abierto. Revista De Educación, 38(1),45-63. http://doi.org/10.17398/0213-9529.38.1.45

Romero, M., Ambròs, A., y Trujillo Sáez, F. (2020). Hábitos lectores de los adolescentes en un ecosistema llamado escuela: factores determinantes en estudiantes de educación secundaria. Investigaciones Sobre Lectura, 2020, (13), 1-34. https://doi.org/10.37132/isl.v0i13.295

Rubio, R. (2017). El proyecto lingüístico de centro como respuesta sistémica al reto de la competencia comunicativa en entornos educativos formales. Análisis de casos. [Tesis doctoral]. Universidad de Cádiz.

Toffler, A. (1979). The Third Wave. Bantam Books

Torrado, M. (2004). Estudios de encuesta. En R. Bisquerra (Coord.), Metodología de la investigación educativa (pp. 231-257). Editorial La Muralla.

Trujillo, F. y Rubio, R. (2014). El PLC como respuesta sistémica al reto de la competencia comunicativa en entornos educativos formales: propuesta de análisis de casos. Lenguaje y textos, (39), 29-38. 


\section{ANEXOS}

\section{ANEXO I}

Autoevaluación sobre las destrezas de la comunicación oral del alumnado (DCOA) Bienvenido a este cuestionario. A partir del siguiente formulario, vas a realizar una evaluación de cómo valoras algunas destrezas relacionadas con la Competencia Comunicativa Oral (CCO) y la regularidad con la que se realizan en clase actividades de comprensión y expresión oral.

Algunos aspectos importantes:

- Las preguntas están formuladas en primera persona porque sólo es necesario conocerse a sí mismo.

- El cuestionario es anónimo y sus respuestas se archivarán de igual forma, de manera que los resultados obtenidos sólo serán utilizados en el marco del presente estudio. Por ello pedimos que respondas libremente intentando ser lo más fiel posible a la realidad.

- No es posible avanzar de página hasta que se haya respondido a todas las cuestiones obligatorias.

- Las respuestas no se guardan a no ser que envíe el cuestionario, por lo que una vez iniciado no se deberá cerrar la pestaña del navegador hasta concluirlo y pulsar 'enviar', tras lo que recibirás un mensaje de confirmación.

Encontrarás tres apartados:

1. La comunicación en el día a día: analiza aspectos propios de la comunicación oral en el día a día.

2. La comunicación en la vida académica: propone evaluar el grado de importancia que se otorga a las diferentes destrezas del alumnado en la vida académica del centro educativo.

3. Práctica de la comunicación oral en el ámbito académico: analiza la frecuencia con la que se realizan actividades relacionadas con la oralidad y las dificultades que puedan presentar

Muchas gracias por colaborar en esta investigación.

Dirección de correo electrónico *

Tu dirección de correo electrónico

\section{Perfil}

En esta sección se recopilarán datos de carácter estadístico que permitan organizar la muestra del estudio.

\subsection{Datos personales}

\subsubsection{Género * \\ ○ Hombre \\ ○ Mujer}




\subsubsection{Edad*}

Tu respuesta

1.2 Datos académicos

1.2.1 Titularidad de los centros en lo que he estudiado *

Pública

$\square$ Privada-concertada

$\square$ Privada

1.2.2 Estoy cursando la opción *

- Enseñanzas académicas para la iniciación al Bachillerato

- Enseñanzas aplicadas para la iniciación a la Formación Profesional

1.2.3 En la modalidad de *

- Ciencias

- Ciencias Sociales y Humanidades

1.2.4 Materias que curso *

Biología

$\square$ Ciencias Aplicadas a la Actividad Empresarial

$\square$ Cine

$\square$ Cultura científica

$\square$ Economía

$\square$ Educación Física

$\square$ Educación Plástica, Visual y Audiovisual

$\square$ Filosofía

$\square$ Física y Química

$\square$ Francés

$\square$ Geografía e Historia

$\square$ Inglés

$\square$ Iniciación a la Actividad Emprendedora y Empresarial

$\square$ Latín

$\square$ Lengua Castellana y Literatura

$\square$ Matemáticas

$\square$ Música

Religión

Tecnología

$\square$ Tecnologías de la Información y la Comunicación

$\square$ Valores Éticos

1.2.5 He repetido en alguna ocasión en ESO *

e-ISSN:2172-7910

Doi:10.25267/Hachetetepe.2021.i22.1205

Universidad de Cádiz 

○ Sí
○ No

1.2.6 Si he marcado Sí en la respuesta anterior, qué curso(s)
$\square \quad 1 \mathrm{ESO}$
2ESO
$3 \mathrm{ESO}$
$4 \mathrm{ESO}$

2. La comunicación en el día a día

Valora tu habilidad en los siguientes aspectos relacionados con la comunicación con tu entorno personal

\subsection{Hablar e interactuar}

Valora tu habilidad en tu día a día con tus amigos, familia,...

2.1.1 Tengo facilidad para mantener una conversación *

\begin{tabular}{llllll}
\hline & 1 & 2 & 3 & 4 & \\
\hline Valor mínimo & $\mathrm{O}$ & $\mathrm{O}$ & $\mathrm{O}$ & $\mathrm{O}$ & Valor máximo
\end{tabular}

2.1.2 Me expreso de manera fluida *

\begin{tabular}{llllll}
\hline & 1 & 2 & 3 & 4 & \\
\hline Valor mínimo & $\mathrm{O}$ & $\mathrm{O}$ & $\mathrm{O}$ & $\mathrm{O}$ & Valor máximo \\
\hline
\end{tabular}

2.1.3 Diferencio cómo y para qué tengo que hablar según sean familia, amigos, profesores, desconocidos, etc. *

\begin{tabular}{llllll} 
& 1 & 2 & 3 & 4 & \\
\hline Valor mínimo & $\mathrm{O}$ & $\mathrm{O}$ & $\mathrm{O}$ & $\mathrm{O}$ & Valor máximo
\end{tabular}

2.1.4 Utilizo un vocabulario variado *

\begin{tabular}{cccccc}
\hline & 1 & 2 & 3 & 4 & \\
\hline Valor mínimo & $\mathrm{O}$ & $\mathrm{O}$ & $\mathrm{O}$ & $\mathrm{O}$ & Valor máximo \\
\hline
\end{tabular}

2.1.5 Evito frases hechas y coletillas *

\begin{tabular}{cccccc}
\hline & 1 & 2 & 3 & 4 & \\
\hline Valor mínimo & $\mathrm{O}$ & $\mathrm{O}$ & $\mathrm{O}$ & $\mathrm{O}$ & Valor máximo \\
\hline
\end{tabular}

2.1.6 Reconozco el humor y la ironía *

\begin{tabular}{llllll}
\hline & 1 & 2 & 3 & 4 & \\
\hline Valor mínimo & $\mathrm{O}$ & $\mathrm{O}$ & $\mathrm{O}$ & $\mathrm{O}$ & Valor máximo \\
\hline
\end{tabular}

2.1.7 Considero importante hablar correctamente para relacionarme con los demás *

\begin{tabular}{rlllll}
\hline & 1 & 2 & 3 & 4 & \\
\hline Valor mínimo & $\mathrm{O}$ & $\mathrm{O}$ & $\mathrm{O}$ & $\mathrm{O}$ & Valor máximo \\
\hline
\end{tabular}

2.1.8 Me gusta comunicarme oralmente sobre todo con personas *

e-ISSN:2172-7910

Doi:10.25267/Hachetetepe.2021.i22.1205

Universidad de Cádiz 


\begin{tabular}{lcccc}
\hline & $\begin{array}{c}1 \\
\text { (Valor mín.) }\end{array}$ & 2 & 3 & $\begin{array}{c}4 \\
\text { (Valor máx.) }\end{array}$ \\
\hline Menores de 12 años & O & O & O & O \\
$\begin{array}{l}\text { Compañeros/as (de 13 a 18 } \\
\text { años) }\end{array}$ & O & O & O & O \\
Jóvenes (de 19 a 25 años) & O & O & O & O \\
$\begin{array}{l}\text { Personas adultas (más de } \\
25 \text { años) }\end{array}$ & O & O & O & O \\
\hline
\end{tabular}

2.1.9 Vocalizo adecuadamente *

\begin{tabular}{cccccc}
\hline & 1 & 2 & 3 & 4 & \\
\hline Valor mínimo & $\mathrm{O}$ & $\mathrm{O}$ & $\mathrm{O}$ & $\mathrm{O}$ & Valor máximo \\
\hline
\end{tabular}

2.1.10 Acompaño la expresión oral con gestos *

\begin{tabular}{llllll} 
& 1 & 2 & 3 & 4 & \\
\hline Valor mínimo & $\mathrm{O}$ & $\mathrm{O}$ & $\mathrm{O}$ & $\mathrm{O}$ & Valor máximo \\
\hline
\end{tabular}

2.1.11 Cuando hablo, suelo opinar con respeto *

\begin{tabular}{rlllll}
\hline & 1 & 2 & 3 & 4 & \\
\hline Valor mínimo & $\mathrm{O}$ & $\mathrm{O}$ & $\mathrm{O}$ & $\mathrm{O}$ & Valor máximo \\
\hline
\end{tabular}

\subsection{Escuchar}

Valora tu habilidad en tu día a día con tus amigos, familia,...

2.2.1 Comprendo lo que escucho en conversaciones *

\begin{tabular}{llllll}
\hline & 1 & 2 & 3 & 4 & \\
\hline Valor mínimo & $\mathrm{O}$ & $\mathrm{O}$ & $\mathrm{O}$ & $\mathrm{O}$ & Valor máximo \\
\hline
\end{tabular}

2.2.2 Escucho con respeto sin distraerme *

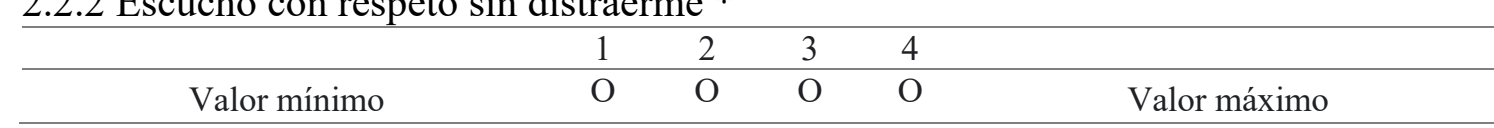

2.2.3 Comprendo el significado de palabras desconocidas por el contexto *

\begin{tabular}{cccccc}
\hline & 1 & 2 & 3 & 4 & \\
\hline Valor mínimo & $\mathrm{O}$ & $\mathrm{O}$ & $\mathrm{O}$ & $\mathrm{O}$ & Valor máximo \\
\hline
\end{tabular}

2.2.4 Comprendo el mensaje de gestos faciales, posturas corporales,.. *

\begin{tabular}{cccccc} 
& 1 & 2 & 3 & 4 & \\
\hline Valor mínimo & $\mathrm{O}$ & $\mathrm{O}$ & $\mathrm{O}$ & $\mathrm{O}$ & Valor máximo \\
\hline
\end{tabular}

2.2.5 Comprendo las noticias de los medios de comunicación *

\begin{tabular}{rrrrrr}
\hline & 1 & 2 & 3 & 4 & \\
\hline Valor mínimo & $\mathrm{O}$ & $\mathrm{O}$ & $\mathrm{O}$ & $\mathrm{O}$ & Valor máximo \\
\hline
\end{tabular}

e-ISSN:2172-7910

Doi:10.25267/Hachetetepe.2021.i22.1205

Universidad de Cádiz 
3. La comunicación en el instituto con el profesor y en las actividades de clase

\subsection{Hablar}

Valora tu habilidad en los siguientes aspectos relacionados con la comunicación en el instituto

3.1.1 Me expreso con fluidez *

\begin{tabular}{llllll}
\hline & 1 & 2 & 3 & 4 & \\
\hline Valor mínimo & $\mathrm{O}$ & $\mathrm{O}$ & $\mathrm{O}$ & $\mathrm{O}$ & Valor máximo \\
\hline
\end{tabular}

3.1.2 Utilizo un vocabulario variado *

$\begin{array}{llllll} & 1 & 2 & 3 & 4 & \\ \text { Valor mínimo } & \mathrm{O} & \mathrm{O} & \mathrm{O} & \mathrm{O} & \text { Valor máximo }\end{array}$

3.1.3 Evito la repetición de frases hechas y coletillas *

\begin{tabular}{llllll} 
& 1 & 2 & 3 & 4 & \\
\hline Valor mínimo & $\mathrm{O}$ & $\mathrm{O}$ & $\mathrm{O}$ & $\mathrm{O}$ & Valor máximo \\
\hline
\end{tabular}

3.1.4 Soy capaz de expresar con palabras lo que pienso y lo que sé *

$\begin{array}{llllll} & 1 & 2 & 3 & 4 & \\ \text { Valor mínimo } & \mathrm{O} & \mathrm{O} & \mathrm{O} & \mathrm{O} & \text { Valor máximo }\end{array}$

3.1.5 Utilizo pausas y silencios para que me entiendan mejor *

\begin{tabular}{llllll}
\hline & 1 & 2 & 3 & 4 & \\
\hline Valor mínimo & $\mathrm{O}$ & $\mathrm{O}$ & $\mathrm{O}$ & $\mathrm{O}$ & Valor máximo \\
\hline
\end{tabular}

3.1.6 Improviso con habilidad sobre cualquier tema *

$\begin{array}{llllll} & 1 & 2 & 3 & 4 & \\ \text { Valor mínimo } & \mathrm{O} & \mathrm{O} & \mathrm{O} & \mathrm{O} & \text { Valor máximo }\end{array}$

3.1.7 Suelo opinar con respeto *

\begin{tabular}{llllll}
\hline & 1 & 2 & 3 & 4 & \\
\hline Valor mínimo & $\mathrm{O}$ & $\mathrm{O}$ & $\mathrm{O}$ & $\mathrm{O}$ & Valor máximo \\
\hline
\end{tabular}

3.1.8 Acompaño mi expresión oral con gestos *

\begin{tabular}{llllll}
\hline & 1 & 2 & 3 & 4 & \\
\hline Valor mínimo & $\mathrm{O}$ & $\mathrm{O}$ & $\mathrm{O}$ & $\mathrm{O}$ & Valor máximo \\
\hline
\end{tabular}

3.1.9 Vocalizo adecuadamente *

\begin{tabular}{llllll}
\hline & 1 & 2 & 3 & 4 & \\
\hline Valor mínimo & $\mathrm{O}$ & $\mathrm{O}$ & $\mathrm{O}$ & $\mathrm{O}$ & Valor máximo \\
\hline
\end{tabular}

3.1.10 Leo con expresividad cualquier texto *

\begin{tabular}{llllll}
\hline & 1 & 2 & 3 & 4 & \\
\hline Valor mínimo & $\mathrm{O}$ & $\mathrm{O}$ & $\mathrm{O}$ & $\mathrm{O}$ & Valor máximo \\
\hline
\end{tabular}




\subsection{Escuchar}

Valora tu habilidad en los siguientes aspectos relacionados con la comunicación en el instituto

3.2.1 Comprendo el sentido global de lo que escucho *

\begin{tabular}{llllll}
\hline & 1 & 2 & 3 & 4 & \\
\hline Valor mínimo & $\mathrm{O}$ & $\mathrm{O}$ & $\mathrm{O}$ & $\mathrm{O}$ & Valor máximo \\
\hline
\end{tabular}

3.2.2 Soy capaz de resumir lo que escucho *

\begin{tabular}{|c|c|c|c|c|c|}
\hline & 1 & 2 & 3 & 4 & \\
\hline Valor mínimo & $\mathrm{O}$ & $\mathrm{O}$ & $\mathrm{O}$ & $\mathrm{O}$ & Valor máximo \\
\hline \multicolumn{6}{|c|}{ 3.2.3 Soy capaz de responder preguntas sobre lo que escucho $*$} \\
\hline & 1 & 2 & 3 & 4 & \\
\hline Valor mínimo & $\mathrm{O}$ & $\mathrm{O}$ & $\mathrm{O}$ & $\mathrm{O}$ & Valor máximo \\
\hline
\end{tabular}

3.2.4 Comprendo palabras desconocidas por el contexto *

\begin{tabular}{llllll}
\hline & 1 & 2 & 3 & 4 & \\
\hline Valor mínimo & $\mathrm{O}$ & $\mathrm{O}$ & $\mathrm{O}$ & $\mathrm{O}$ & Valor máximo \\
\hline
\end{tabular}

3.2.5 Escucho con respeto y sin distrarme *

\begin{tabular}{rrrrrr}
\hline & 1 & 2 & 3 & 4 & \\
\hline Valor mínimo & $\mathrm{O}$ & $\mathrm{O}$ & $\mathrm{O}$ & $\mathrm{O}$ & Valor máximo \\
\hline
\end{tabular}

3.2.6 Comprendo el mensaje de gestos faciales, posturas corporales,... *

\begin{tabular}{cccccc}
\hline & 1 & 2 & 3 & 4 & \\
\hline Valor mínimo & $\mathrm{O}$ & $\mathrm{O}$ & $\mathrm{O}$ & $\mathrm{O}$ & Valor máximo \\
\hline
\end{tabular}

3.3 Habilidades en la exposición

Valora tu habilidad en los siguientes aspectos relacionados con la comunicación en el instituto

3.3.1 Hago un esquema para preparar mis exposiciones *

\begin{tabular}{cccccc} 
& \multicolumn{1}{c}{} & \\
\hline Valor mínimo & 1 & 2 & 3 & 4 & \\
\hline
\end{tabular}

3.3.2 Varío el mensaje según mi intención (entretenimiento, información, discusión, exposición,...)*

\begin{tabular}{llllll} 
& 1 & 2 & 3 & 4 & \\
\hline Valor mínimo & $\mathrm{O}$ & $\mathrm{O}$ & $\mathrm{O}$ & $\mathrm{O}$ & Valor máximo \\
\hline
\end{tabular}

3.3.3 Suelo apoyar una exposición en ayudas visuales (esquemas, gráficos, proyecciones,...)*

\begin{tabular}{cccccc} 
& 1 & 2 & 3 & 4 & \\
\hline Valor mínimo & $\mathrm{O}$ & $\mathrm{O}$ & $\mathrm{O}$ & $\mathrm{O}$ & Valor máximo \\
\hline
\end{tabular}

3.3.4 Desarrollo las ideas ordenadamente *

e-ISSN:2172-7910

Doi:10.25267/Hachetetepe.2021.i22.1205

Universidad de Cádiz 


\begin{tabular}{llllll}
\hline & 1 & 2 & 3 & 4 & \\
\hline Valor mínimo & $\mathrm{O}$ & $\mathrm{O}$ & $\mathrm{O}$ & $\mathrm{O}$ & Valor máximo \\
\hline
\end{tabular}

3.3.5 Distingo los conceptos principales de los secundarios *

\begin{tabular}{cccccc} 
& 1 & 2 & 3 & 4 & \\
\hline Valor mínimo & $\mathrm{O}$ & $\mathrm{O}$ & $\mathrm{O}$ & $\mathrm{O}$ & Valor máximo \\
\hline
\end{tabular}

3.3.6 Puedo explicar con sencillez y claridad temas de cierta complejidad *

\begin{tabular}{rrrrrr} 
& 1 & 2 & 3 & 4 & \\
\hline Valor mínimo & $\mathrm{O}$ & $\mathrm{O}$ & $\mathrm{O}$ & $\mathrm{O}$ & Valor máximo \\
\hline
\end{tabular}

3.3.7 Miro a todo el mundo cuando expongo *

\begin{tabular}{llllll} 
& 1 & 2 & 3 & 4 & \\
\hline Valor mínimo & $\mathrm{O}$ & $\mathrm{O}$ & $\mathrm{O}$ & $\mathrm{O}$ & Valor máximo \\
\hline
\end{tabular}

3.3.8 Soy capaz de utilizar un vocabulario específico del tema que trato *

\begin{tabular}{cccccc}
\hline & 1 & 2 & 3 & 4 & \\
\hline Valor mínimo & $\mathrm{O}$ & $\mathrm{O}$ & $\mathrm{O}$ & $\mathrm{O}$ & Valor máximo \\
\hline
\end{tabular}

3.3.8 Soy capaz de responder a preguntas y comentarios durante mi exposición y relacionarlo con mis propias ideas *

\begin{tabular}{cccccc}
\hline & 1 & 2 & 3 & 4 & \\
\hline Valor mínimo & $\mathrm{O}$ & $\mathrm{O}$ & $\mathrm{O}$ & $\mathrm{O}$ & Valor máximo \\
\hline
\end{tabular}

3.4 Capacidad de autoevaluación

Valora tu habilidad en los siguientes aspectos relacionados con la comunicación en el instituto

3.4.1 Soy capaz de autoevaluar mis intervenciones *

\begin{tabular}{cccccc} 
& 1 & 2 & 3 & 4 & \\
\hline Valor mínimo & $\mathrm{O}$ & $\mathrm{O}$ & $\mathrm{O}$ & $\mathrm{O}$ & Valor máximo \\
\hline
\end{tabular}

3.4.2 Soy capaz de evaluar las intervenciones de mis compañeros/as *

\begin{tabular}{cccccc}
\hline & 1 & 2 & 3 & 4 & \\
\hline Valor mínimo & $\mathrm{O}$ & $\mathrm{O}$ & $\mathrm{O}$ & $\mathrm{O}$ & Valor máximo \\
\hline
\end{tabular}

3.4.3 Tengo interés por desarrollar mis habilidades comunicativas *

Valor mínimo

$\begin{array}{llll}1 & 2 & 3 & 4 \\ \mathrm{O} & \mathrm{O} & \mathrm{O} & \mathrm{O}\end{array}$

Valor máximo 
4. Práctica de la comunicación oral en el ámbito académico

4.1 Indica la frecuencia con la que se realizan las siguientes actividades en clase, con independencia de la asignatura en la que se practique y DONDE SEAS EL ESPECTADOR (no participas activamente) *

\begin{tabular}{|c|c|c|c|c|}
\hline & Nunca & Puntualmente & Con frecuencia & A diario \\
\hline Entrevista & $\mathrm{O}$ & $\mathrm{O}$ & $\mathrm{O}$ & $\mathrm{O}$ \\
\hline Debate & $\mathrm{O}$ & $\mathrm{O}$ & $\mathrm{O}$ & $\mathrm{O}$ \\
\hline Exposición & $\mathrm{O}$ & $\mathrm{O}$ & $\mathrm{O}$ & $\mathrm{O}$ \\
\hline $\begin{array}{l}\text { Instrucciones orales para } \\
\text { realizar actividades } \\
\text { complejas }\end{array}$ & $\mathrm{O}$ & $\mathrm{O}$ & $\mathrm{O}$ & $\mathrm{O}$ \\
\hline Corrección en voz alta & $\mathrm{O}$ & $\mathrm{O}$ & $\mathrm{O}$ & $\mathrm{O}$ \\
\hline Trabajo en grupos en el aula & $\mathrm{O}$ & $\mathrm{O}$ & $\mathrm{O}$ & $\mathrm{O}$ \\
\hline $\begin{array}{l}\text { Creación de archivos de } \\
\text { audio }\end{array}$ & $\mathrm{O}$ & $\mathrm{O}$ & $\mathrm{O}$ & $\mathrm{O}$ \\
\hline Creación de vídeos & $\mathrm{O}$ & $\mathrm{O}$ & $\mathrm{O}$ & $\mathrm{O}$ \\
\hline Comentario de imágenes & $\mathrm{O}$ & $\mathrm{O}$ & $\mathrm{O}$ & $\mathrm{O}$ \\
\hline Representación teatral & $\mathrm{O}$ & $\mathrm{O}$ & $\mathrm{O}$ & $\mathrm{O}$ \\
\hline Canciones & $\mathrm{O}$ & $\mathrm{O}$ & $\mathrm{O}$ & $\mathrm{O}$ \\
\hline Películas de cine & $\mathrm{O}$ & $\mathrm{O}$ & $\mathrm{O}$ & $\mathrm{O}$ \\
\hline $\begin{array}{l}\text { Explicación de vocabulario } \\
\text { o tecnicismos }\end{array}$ & $\mathrm{O}$ & $\mathrm{O}$ & $\mathrm{O}$ & $\mathrm{O}$ \\
\hline Audiciones & $\mathrm{O}$ & $\mathrm{O}$ & $\mathrm{O}$ & $\mathrm{O}$ \\
\hline $\begin{array}{l}\text { Actividades de comprensión } \\
\text { de vídeos o audios }\end{array}$ & $\mathrm{O}$ & $\mathrm{O}$ & $\mathrm{O}$ & $\mathrm{O}$ \\
\hline
\end{tabular}

4.2 Indica la frecuencia con la que se realizan las siguientes actividades en clase, con independencia de la asignatura en la que se practique y DONDE SEAS PARTICIPANTE ACTIVO *

\begin{tabular}{lcccc}
\hline & Nunca & Puntualmente & Con frecuencia & A diario \\
\hline Entrevista & $\mathrm{O}$ & $\mathrm{O}$ & $\mathrm{O}$ & $\mathrm{O}$ \\
Debate & $\mathrm{O}$ & $\mathrm{O}$ & $\mathrm{O}$ & $\mathrm{O}$ \\
Exposición & $\mathrm{O}$ & $\mathrm{O}$ & $\mathrm{O}$ & $\mathrm{O}$ \\
\hline
\end{tabular}


Instrucciones orales para realizar actividades

complejas

Corrección en voz alta

Trabajo en grupos en el aula

Creación de archivos de audio

Creación de vídeos

Comentario de imágenes

Representación teatral

Canciones

Películas de cine

Explicación de vocabulario o tecnicismos

Audiciones

Actividades de comprensión de vídeos o audios

$\begin{array}{llll}\mathrm{O} & \mathrm{O} & \mathrm{O} & \mathrm{O}\end{array}$

$\mathrm{O}$ $\mathrm{O}$

$\mathrm{O}$

$\mathrm{O}$

$\mathrm{O}$

$\mathrm{O}$

O

O

$\mathrm{O}$

$\mathrm{O}$

$\mathrm{O}$

$\mathrm{O}$

$\mathrm{O}$

$\begin{array}{llll}\mathrm{O} & \mathrm{O} & \mathrm{O} & \mathrm{O}\end{array}$

O

O

O

O

O

O

O

O

O

O

O

O

O

O

O

O

O

O

O

O

O

O

O

O

O

O

O

O

4.3 De estas actividades indica cuáles son las más difíciles para ti *

\begin{tabular}{|c|c|c|c|c|}
\hline & 1 (Sencillas) & 2 & 3 & 4 (Difíciles) \\
\hline Entrevista & $\mathrm{O}$ & $\mathrm{O}$ & $\mathrm{O}$ & $\mathrm{O}$ \\
\hline Debate & $\mathrm{O}$ & $\mathrm{O}$ & $\mathrm{O}$ & $\mathrm{O}$ \\
\hline Exposición & $\mathrm{O}$ & $\mathrm{O}$ & $\mathrm{O}$ & $\mathrm{O}$ \\
\hline $\begin{array}{l}\text { Instrucciones orales para } \\
\text { realizar actividades } \\
\text { complejas }\end{array}$ & $\mathrm{O}$ & $\mathrm{O}$ & $\mathrm{O}$ & $\mathrm{O}$ \\
\hline Corrección en voz alta & $\mathrm{O}$ & $\mathrm{O}$ & $\mathrm{O}$ & $\mathrm{O}$ \\
\hline Trabajo en grupos en el aula & $\mathrm{O}$ & $\mathrm{O}$ & $\mathrm{O}$ & $\mathrm{O}$ \\
\hline $\begin{array}{l}\text { Creación de archivos de } \\
\text { audio }\end{array}$ & $\mathrm{O}$ & $\mathrm{O}$ & $\mathrm{O}$ & $\mathrm{O}$ \\
\hline Creación de vídeos & $\mathrm{O}$ & $\mathrm{O}$ & $\mathrm{O}$ & $\mathrm{O}$ \\
\hline Comentario de imágenes & $\mathrm{O}$ & $\mathrm{O}$ & $\mathrm{O}$ & $\mathrm{O}$ \\
\hline Representación teatral & $\mathrm{O}$ & $\mathrm{O}$ & $\mathrm{O}$ & $\mathrm{O}$ \\
\hline
\end{tabular}

e-ISSN:2172-7910 
Canciones

\section{$\mathrm{O}$}

$\mathrm{O}$

$\mathrm{O}$

Explicación de vocabulario o tecnicismos

\section{Audiciones}

Actividades de comprensión de vídeos o audios

O

O

O

O

O

O

$\mathrm{O}$
$\mathrm{O}$

O

O

$\mathrm{O}$

O

4.4 ¿Crees que tus capacidades de expresarte y comprender textos orales se tienen en cuenta en tus notas?

\begin{tabular}{cccccc}
\hline & 1 & 2 & 3 & 4 & \\
\hline Valor mínimo & $\mathrm{O}$ & $\mathrm{O}$ & $\mathrm{O}$ & $\mathrm{O}$ & Valor máximo \\
\hline
\end{tabular}

4.5 En caso de ser evaluado/a ¿De qué manera lo eres? *

\begin{tabular}{lcccc} 
& $\begin{array}{l}1 \\
\text { Valor mínimo }\end{array}$ & 2 & 3 & $\begin{array}{c}4 \\
\text { Rúbricas }\end{array}$ \\
Registros de observación & $\mathrm{O}$ & $\mathrm{O}$ & $\mathrm{O}$ & $\mathrm{O}$ \\
Portafolios & $\mathrm{O}$ & $\mathrm{O}$ & $\mathrm{O}$ & $\mathrm{O}$ \\
Exámenes orales & $\mathrm{O}$ & $\mathrm{O}$ & $\mathrm{O}$ & $\mathrm{O}$ \\
Co-evaluación & $\mathrm{O}$ & $\mathrm{O}$ & $\mathrm{O}$ & $\mathrm{O}$ \\
Autoevaluación & $\mathrm{O}$ & $\mathrm{O}$ & $\mathrm{O}$ & $\mathrm{O}$ \\
Lo desconozco & $\mathrm{O}$ & $\mathrm{O}$ & $\mathrm{O}$ & $\mathrm{O}$ \\
& $\mathrm{O}$ & $\mathrm{O}$ & $\mathrm{O}$ & $\mathrm{O}$ \\
\hline
\end{tabular}

4.6 ¿En qué asignaturas te han explicado en alguna ocasión qué debes hacer para mejorar tu forma de hablar, escuchar o interactuar con otros? * 


\section{ANEXO II \\ Destrezas de la comunicación oral del alumnado para el profesorado (DCOP)}

Bienvenido a este cuestionario. A partir del siguiente formulario, vas a realizar una evaluación de cómo valoras algunas destrezas relacionadas con la Competencia Comunicativa Oral (CCO) del ALUMNADO -no la tuya propia-, ya sea desde la expresión o la comprensión. Igualmente se valorará la regularidad con la que se realizan en clase actividades de comprensión y expresión oral.

El presente cuestionario forma parte del trabajo de campo para la tesis doctoral de Alberto Corpas Martos en la Universidad de Cádiz. El tiempo estimado para la realización del cuestionario oscila alrededor de los 5 minutos.

Algunos aspectos importantes:

- Las preguntas están formuladas en primera persona porque sólo es necesario conocerse a sí mismo.

- El cuestionario es anónimo y sus respuestas se archivarán de igual forma, de manera que los resultados obtenidos sólo serán utilizados en el marco del presente estudio. Por ello pedimos que respondas libremente intentando ser lo más fiel posible a la realidad.

- No es posible avanzar de página hasta que se haya respondido a todas las cuestiones obligatorias.

- Las respuestas no se guardan a no ser que envíe el cuestionario, por lo que una vez iniciado no se deberá cerrar la pestaña del navegador hasta concluirlo y pulsar 'enviar', tras lo que recibirás un mensaje de confirmación.

Encontrará dos apartados:

1. La oralidad en el aula: analiza la presencia y tratamiento de la oralidad en el aula.

2. La comunicación en la vida académica: propone evaluar el grado de importancia que se otorga a las diferentes destrezas del alumnado en la vida académica del centro educativo.

Muchas gracias por colaborar en esta investigación.

Dirección de correo electrónico *

Tu dirección de correo electrónico

\section{Perfil profesional}

En esta sección se recopilarán datos de carácter estadístico que permitan organizar la muestra del estudio. 
1.1 Datos personales
1.1.1 Género *
○ Hombre
○ Mujer

\subsubsection{Edad*}

1.2 Datos laborales

1.2.1 Años de experiencia docente *

1.2.2 Antigüedad en el centro actual *

1.2.3 Titularidad de los centros donde he ejercido la docencia *

- Pública

- Privada-Concertada

○ Privada

1.2.4 Áreas de conocimiento que imparto *

- Biología y Geología

- Cambios sociales y género

- Ciencias aplciadas a la actividad empresarial

- Cultura científica

- Economía

- Educación Física

- Educación Plástica, Visual y Audiovisual

- Filosofía

- Física y Química

- Francés

- Geografía e Historia

○ Inglés

- Iniciación a la Actividad Emprendedora y Empresarial

- Latín

- Lengua Castellana y Literatura

- Matemáticas

○ Música 
○ Religión

- Tecnología

- Tecnologías de la Información y la Comunicación

○ Valores Éticos

o Otro:

1.2.5 Lenguas en las que imparto docencia*

- Castellano

- Francés

○ Inglés

○ Lenguas clásicas

o Otro:

1.3 Datos académicos

1.3.1 Titulación de acceso a la función docente (licenciatura/grado y especialidad) *

1.3.2 Año de finalización de los estudios reseñados en la pregunta anterior *

1.3.3 Otras diplomaturas, licenciaturas o grados *

1.3.4 He realizado o estoy realizando estudios de posgrado *

○ Doctorado

- Experto universitario

○ Máster

○ No

O Otro:

1.3.5 En caso afirmativo a la pregunta anterior, cuál es la titulación

1.3.6 Formación inicial de acceso a la labor docente *

CAP (Curso de Adaptación Pedagógica)

MAES (Máster Universitario en Profesorado de Educación Secundaria)

Diplomado en Magisterio

Graduado en Magisterio

Otro: 
1.4 Formación continua

1.4.1 He realizado cursos de formación relacionados con la oralidad *

Organizados por el CEP

Formación en el propio centro por necesidades específicas

Formación externa solicitada de manera individual

Ninguno

Otro:

1.4.2 En caso afirmativo a la pregunta anterior, sobre qué temáticas

\subsection{Experiencias positivas}

1.5.1 Recuerdo como experiencia muy positiva relacionada con el uso de la oralidad en el aula...

2. La oralidad en el aula

Valora la presencia que tiene la oralidad en el aula y la importancia que recibe en tu departamento didáctico y en el centro

2. La oralidad en el aula

En la oralidad incluimos tres destrezas fundamentales: hablar, escuchar e interactuar. No obstante, estas pueden aparecer apoyadas por la lectura y la escritura.

2.1 El nivel de comunicación oral de mi alumnado es *

$\begin{array}{lllll}1 & 2 & 3 & 4\end{array}$

Valor mínimo

$\mathrm{O} \quad \mathrm{O} \quad \mathrm{O} \quad \mathrm{O}$

Valor máximo

2.2 Importancia que le concedo en mi materia al desarrollo de las capacidades comunicativas orales del alumnado *

\begin{tabular}{llllll}
\hline & 1 & 2 & 3 & 4 & \\
\hline Valor mínimo & $\mathrm{O}$ & $\mathrm{O}$ & $\mathrm{O}$ & $\mathrm{O}$ & Valor máximo \\
\hline
\end{tabular}

2.3 ¿Desde mi materia se puede contribuir al desarrollo de la comunicación oral? (SÍ o NO y breve justificación) *

2.4 El currículo de mi materia incluye destrezas orales tanto en los objetivos, contenidos como en los criterios de evaluación *
○ Sí
o No
- Lo desconozco

2.5 Realizo actividades orales como instrumento de evaluación *

$\begin{array}{llll}1 & 2 & 3 & 4\end{array}$

e-ISSN:2172-7910

Doi:10.25267/Hachetetepe.2021.i22.1205

Universidad de Cádiz 


$\begin{array}{llllll}\text { Valor mínimo } & \mathrm{O} & \mathrm{O} & \mathrm{O} & \mathrm{O} & \text { Valor máximo }\end{array}$

2.6 Herramientas con las que evalúo

Portafolio oral

$\square$ Exposiciones orales

$\square$ Entrevistas por parejas

$\square$ Role play

Discusión en pareja o en grupos

Apps de cuestionarios (Kahoot, Plickers,...)

Otro:

2.7 Procedimientos con los que evaluamos la oralidad en clase

$\square$ Observación directa

$\square$ Correciones en gran grupo

Co-evaluación entre el alumnado

$\square$ Auto-evaluación del alumnado

Otro:

2.8 Instrumentos con los que evaluamos

Rúbricas

Registros de observación

Diario de aula

Portafolio

$\square$ Exámenes orales

Otro:

2.9 Dificultades para el trabajo de la oralidad en el aula *

$\square$ Ratio de alumnado

$\square$ Baja preparación de las actividades por parte del alumnado

$\square$ No me siento capaz de evaluarlo

$\square$ Exceso de contenidos del área

$\square$ Debe trabajarse en las áreas lingüísticas

$\square$ Mi especialidad no puede contribuir al desarrollo de la comunicación oral

$\square$ No me parece relevante

$\square$ Es difícil motivar al alumnado

$\square$ Problemas de ruido y convivencia

$\square$ El alumnado presenta dificultades para hablar en público

Es una actividad necesaria que no presenta especiales dificultades

Los libros de textos no contribuyen al desarrollo de la oralidad en el aula

$\square$ (Solo si imparto una lengua extranjera) Por el bajo nivel de competencia lingüística del alumnado

Otro:

2.10 Frecuencia de las siguientes actividades en clase *

\begin{tabular}{lcccc}
\hline & Nunca & Puntualmente & Con frecuencia & A diario \\
\hline Entrevista & $\mathrm{O}$ & $\mathrm{O}$ & $\mathrm{O}$ & $\mathrm{O}$ \\
Debate & $\mathrm{O}$ & $\mathrm{O}$ & $\mathrm{O}$ & $\mathrm{O}$ \\
Exposición & $\mathrm{O}$ & $\mathrm{O}$ & $\mathrm{O}$ & $\mathrm{O}$
\end{tabular}


Instrucciones orales para realizar actividades

complejas

Corrección en voz alta

Trabajo en grupos en el aula

Creación de archivos de audio

Creación de vídeos

Comentario de imágenes

Representación teatral

Canciones

Películas de cine

Explicación de vocabulario o tecnicismos

Audiciones

Actividades de comprensión de vídeos o audios
$\mathrm{O}$

$\mathrm{O}$

$\mathrm{O}$

$+2$

\begin{abstract}
$\mathrm{O}$
\end{abstract}
$\mathrm{O}$

$\mathrm{O}$

O

$\mathrm{O}$

$\mathrm{O}$

$\mathrm{O}$

$\mathrm{O}$

O

O

O

O

\begin{abstract}
O
\end{abstract}
O

$\mathrm{O}$

O

O

O

O

O

O

O

O

O

$\mathrm{O}$

O

O

O

O

O

O

O

O

O

O

O

O

O

O

O

O

O

O

O

2.11 Tipo de texto que predomina en las actividades relacionadas con la oralidad * $\square$ Correción de actividades

$\square$ Textos explicativos de las lecciones de clase

$\square$ Textos argumentativos que incluyen valoraciones críticas

$\square$ Textos instructivos para la realización de actividades

$\square$ Textos narrativos basados en acontecimientos reales

$\square$ Textos narrativos basados en hechos de ficción

Textos informativos propios de los medios de comunicación

2.12 Orden de preferencia desde tu materia para las siguientes destrezas * Orden de Primero a Quinto, no pudiendo repetir el valor en ninguna columna

\begin{tabular}{lccccc}
\hline & 1 Primero & 2 Segundo & 3 Tercero & 4 Cuarto & 5 Quinto \\
\hline Hablar & $\mathrm{O}$ & $\mathrm{O}$ & $\mathrm{O}$ & $\mathrm{O}$ & $\mathrm{O}$ \\
Escuchar & $\mathrm{O}$ & $\mathrm{O}$ & $\mathrm{O}$ & $\mathrm{O}$ & $\mathrm{O}$ \\
Leer & $\mathrm{O}$ & $\mathrm{O}$ & $\mathrm{O}$ & $\mathrm{O}$ & $\mathrm{O}$ \\
Escribir & $\mathrm{O}$ & $\mathrm{O}$ & $\mathrm{O}$ & $\mathrm{O}$ & $\mathrm{O}$ \\
Interactuar & $\mathrm{O}$ & $\mathrm{O}$ & $\mathrm{O}$ & $\mathrm{O}$ & $\mathrm{O}$ \\
\hline
\end{tabular}


2.13 Trabajo que se realiza desde mi departamento didáctico sobre la oralidad *

\begin{tabular}{llllll}
\hline & 1 & 2 & 3 & 4 & \\
\hline Valor mínimo & $\mathrm{O}$ & $\mathrm{O}$ & $\mathrm{O}$ & $\mathrm{O}$ & Valor máximo \\
\hline
\end{tabular}

2.14 Las destrezas lingüísticas están diferenciadas en la programación del departamento desde el punto de vista de la evaluación *

○ Sí

○ No

2.15 Si existe, ¿qué porcentaje tiene dentro del cálculo de la nota de cada evaluación la destreza 'hablar'?

2.16 Si existe, ¿qué porcentaje tiene dentro del cálculo de la nota de cada evaluación la destreza 'escuchar'?

2.17 Si existe, ¿qué porcentaje tiene dentro del cálculo de la nota de cada evaluación la destreza 'interactuar'?

2.18 Trabajo que se realiza desde mi departamento didáctico de la oralidad en coordinación con otros departamentos *

\begin{tabular}{llllll}
\hline & 1 & 2 & 3 & 4 & \\
\hline Valor mínimo & $\mathrm{O}$ & $\mathrm{O}$ & $\mathrm{O}$ & $\mathrm{O}$ & Valor máximo \\
\hline
\end{tabular}

2.19 Importancia que tiene el desarrollo de las capacidades comunicativas orales del alumnado en el centro *

\begin{tabular}{llllll}
\hline & 1 & 2 & 3 & 4 & \\
\hline Valor mínimo & $\mathrm{O}$ & $\mathrm{O}$ & $\mathrm{O}$ & $\mathrm{O}$ & Valor máximo \\
\hline
\end{tabular}

3. La comunicación en la vida académica

Valora la importancia que tienen LAS DESTREZAS DE SU ALUMNADO (no las propias) en las actividades que incluyan comunicación oral

\subsection{Hablar}

Importancia de las siguientes capacidades del alumnado

3.1.1 Fluidez en la expresión *

\begin{tabular}{llllll}
\hline & 1 & 2 & 3 & 4 & \\
\hline Valor mínimo & $\mathrm{O}$ & $\mathrm{O}$ & $\mathrm{O}$ & $\mathrm{O}$ & Valor máximo \\
\hline
\end{tabular}

\subsubsection{Vocabulario variado *}

\begin{tabular}{llllll}
\hline & 1 & 2 & 3 & 4 & \\
\hline Valor mínimo & $\mathrm{O}$ & $\mathrm{O}$ & $\mathrm{O}$ & $\mathrm{O}$ & Valor máximo \\
\hline
\end{tabular}

3.1.3 Omisión de frases hechas y coletillas *

\begin{tabular}{llllll}
\hline & 1 & 2 & 3 & 4 & \\
\hline Valor mínimo & $\mathrm{O}$ & $\mathrm{O}$ & $\mathrm{O}$ & $\mathrm{O}$ & Valor máximo \\
\hline
\end{tabular}




\subsubsection{Respuestas bien razonadas *}

\begin{tabular}{llllll}
\hline & 1 & 2 & 3 & 4 & \\
\hline Valor mínimo & $\mathrm{O}$ & $\mathrm{O}$ & $\mathrm{O}$ & $\mathrm{O}$ & Valor máximo \\
\hline
\end{tabular}

3.1.5 Pausas y silencios *

\begin{tabular}{llllll}
\hline & 1 & 2 & 3 & 4 & \\
\hline Valor mínimo & $\mathrm{O}$ & $\mathrm{O}$ & $\mathrm{O}$ & $\mathrm{O}$ & Valor máximo \\
\hline
\end{tabular}

3.1.6 Improvisación con habilidad sobre cualquier tema *

\begin{tabular}{llllll}
\hline & 1 & 2 & 3 & 4 & \\
\hline Valor mínimo & $\mathrm{O}$ & $\mathrm{O}$ & $\mathrm{O}$ & $\mathrm{O}$ & Valor máximo \\
\hline
\end{tabular}

3.1.7 Respeto al opinar *

\begin{tabular}{llllll}
\hline & 1 & 2 & 3 & 4 & \\
\hline Valor mínimo & $\mathrm{O}$ & $\mathrm{O}$ & $\mathrm{O}$ & $\mathrm{O}$ & Valor máximo \\
\hline
\end{tabular}

3.1.8 Gestos que acompañen el mensaje verbal *

\begin{tabular}{llllll}
\hline & 1 & 2 & 3 & 4 & \\
\hline Valor mínimo & $\mathrm{O}$ & $\mathrm{O}$ & $\mathrm{O}$ & $\mathrm{O}$ & Valor máximo \\
\hline
\end{tabular}

3.1.9 Vocalización correcta *

\begin{tabular}{llllll}
\hline & 1 & 2 & 3 & 4 & \\
\hline Valor mínimo & $\mathrm{O}$ & $\mathrm{O}$ & $\mathrm{O}$ & $\mathrm{O}$ & Valor máximo \\
\hline
\end{tabular}

3.1.10 Lectura expresiva *

\begin{tabular}{llllll}
\hline & 1 & 2 & 3 & 4 & \\
\hline Valor mínimo & $\mathrm{O}$ & $\mathrm{O}$ & $\mathrm{O}$ & $\mathrm{O}$ & Valor máximo \\
\hline
\end{tabular}

\subsection{Escuchar}

Importancia de las siguientes capacidades del alumnado

3.2.1 Comprensión global de lo escuchado *

\begin{tabular}{llllll}
\hline & 1 & 2 & 3 & 4 & \\
\hline Valor mínimo & $\mathrm{O}$ & $\mathrm{O}$ & $\mathrm{O}$ & $\mathrm{O}$ & Valor máximo \\
\hline
\end{tabular}

3.2.2 Capacidad de resumir lo escuchado *

\begin{tabular}{llllll}
\hline & 1 & 2 & 3 & 4 & \\
\hline Valor mínimo & $\mathrm{O}$ & $\mathrm{O}$ & $\mathrm{O}$ & $\mathrm{O}$ & Valor máximo \\
\hline
\end{tabular}

3.2.3 Capacidad de responder cuestiones relacionadas con lo escuchado *

\begin{tabular}{llllll}
\hline & 1 & 2 & 3 & 4 & \\
\hline Valor mínimo & $\mathrm{O}$ & $\mathrm{O}$ & $\mathrm{O}$ & $\mathrm{O}$ & Valor máximo \\
\hline
\end{tabular}

3.2.4 Comprensión de palabras desconocidas por el contexto *

\begin{tabular}{llllll}
\hline & 1 & 2 & 3 & 4 & \\
\hline Valor mínimo & $\mathrm{O}$ & $\mathrm{O}$ & $\mathrm{O}$ & $\mathrm{O}$ & Valor máximo \\
\hline
\end{tabular}


3.2.5 Escucha respetuosa sin distracciones ni interrupciones *

\begin{tabular}{llllll}
\hline & 1 & 2 & 3 & 4 & \\
\hline Valor mínimo & $\mathrm{O}$ & $\mathrm{O}$ & $\mathrm{O}$ & $\mathrm{O}$ & Valor máximo \\
\hline
\end{tabular}

3.2.6 Comprensión de gestos faciales, posturas corporales,... *

\begin{tabular}{llllll}
\hline & 1 & 2 & 3 & 4 & \\
\hline Valor mínimo & $\mathrm{O}$ & $\mathrm{O}$ & $\mathrm{O}$ & $\mathrm{O}$ & Valor máximo \\
\hline
\end{tabular}

3.3 Habilidades en la exposición

Importancia de las siguientes capacidades del alumnado

\subsubsection{Realización de un esquema previo *}

\begin{tabular}{llllll}
\hline & 1 & 2 & 3 & 4 & \\
\hline Valor mínimo & $\mathrm{O}$ & $\mathrm{O}$ & $\mathrm{O}$ & $\mathrm{O}$ & Valor máximo \\
\hline
\end{tabular}

3.3.2 Adecuación del mensaje a la intención (entretenimiento, información, discusión, exposición,...)*

\begin{tabular}{llllll} 
& 1 & 2 & 3 & 4 & \\
\hline Valor mínimo & $\mathrm{O}$ & $\mathrm{O}$ & $\mathrm{O}$ & $\mathrm{O}$ & Valor máximo
\end{tabular}

3.3.3 Apoyo en ayudas visuales (esquemas, gráficos, presentaciones,...) *

\begin{tabular}{llllll}
\hline & 1 & 2 & 3 & 4 & \\
\hline Valor mínimo & $\mathrm{O}$ & $\mathrm{O}$ & $\mathrm{O}$ & $\mathrm{O}$ & Valor máximo \\
\hline
\end{tabular}

3.3.4 Desarrollo ordenado de las ideas *

\begin{tabular}{llllll}
\hline & 1 & 2 & 3 & 4 & \\
\hline Valor mínimo & $\mathrm{O}$ & $\mathrm{O}$ & $\mathrm{O}$ & $\mathrm{O}$ & Valor máximo \\
\hline
\end{tabular}

3.3.5 Distinción entre los conceptos principales y los secundarios *

\begin{tabular}{llllll}
\hline & 1 & 2 & 3 & 4 & \\
\hline Valor mínimo & $\mathrm{O}$ & $\mathrm{O}$ & $\mathrm{O}$ & $\mathrm{O}$ & Valor máximo \\
\hline
\end{tabular}

3.3.6 Sencillez y claridad en la explicación de temas de cierta complejidad *

\begin{tabular}{|c|c|c|c|c|c|}
\hline & 1 & 2 & 3 & 4 & \\
\hline Valor mínimo & $\mathrm{O}$ & $\mathrm{O}$ & $\mathrm{O}$ & $\mathrm{O}$ & Valor máximo \\
\hline
\end{tabular}

3.3.7 Contacto visual hacia todo el auditorio *

\begin{tabular}{llllll}
\hline & 1 & 2 & 3 & 4 & \\
\hline Valor mínimo & $\mathrm{O}$ & $\mathrm{O}$ & $\mathrm{O}$ & $\mathrm{O}$ & Valor máximo \\
\hline
\end{tabular}

3.3.8 Uso de un vocabulario específico relacionado con el tema *

\begin{tabular}{llllll}
\hline & 1 & 2 & 3 & 4 & \\
\hline Valor mínimo & $\mathrm{O}$ & $\mathrm{O}$ & $\mathrm{O}$ & $\mathrm{O}$ & Valor máximo \\
\hline
\end{tabular}

3.3.9 Capacidad de formular ideas y opiniones con precisión y relacionando las intervenciones con la de otros hablantes (interacción) * 


$\begin{array}{llllll}\text { Valor mínimo } & \mathrm{O} & \mathrm{O} & \mathrm{O} & \mathrm{O} & \text { Valor máximo }\end{array}$

3.4 Capacidad de autoevaluación Importancia de las siguientes capacidades del alumnado

3.4.1 Capacidad de autoevaluar su producción oral *

\begin{tabular}{llllll}
\hline & 1 & 2 & 3 & 4 & \\
\hline Valor mínimo & $\mathrm{O}$ & $\mathrm{O}$ & $\mathrm{O}$ & $\mathrm{O}$ & Valor máximo \\
\hline
\end{tabular}

3.4.2 Capacidad de evaluar la producción oral de sus compañeros/as *

\begin{tabular}{llllll}
\hline & 1 & 2 & 3 & 4 & \\
\hline Valor mínimo & $\mathrm{O}$ & $\mathrm{O}$ & $\mathrm{O}$ & $\mathrm{O}$ & Valor máximo
\end{tabular}

3.4.3 Interés por desarrollar sus habilidades comunicativas *

\begin{tabular}{llllll}
\hline & 1 & 2 & 3 & 4 & \\
\hline Valor mínimo & $\mathrm{O}$ & $\mathrm{O}$ & $\mathrm{O}$ & $\mathrm{O}$ & Valor máximo \\
\hline
\end{tabular}


ANEXO III

\begin{tabular}{|c|c|c|c|}
\hline \multicolumn{4}{|c|}{ Evaluación del fomento de la competencia comunicativa oral } \\
\hline ITEM & SÍ & NO & OBSERVACIONES \\
\hline \multicolumn{4}{|c|}{ Planes y programas } \\
\hline \multicolumn{4}{|l|}{ El centro cuenta con un PLC } \\
\hline \multicolumn{4}{|l|}{ El centro participa en el programa ComunicA } \\
\hline \multicolumn{4}{|l|}{$\begin{array}{l}\text { Se promueven actividades a nivel de centro } \\
\text { que favorezcan las oralidad }\end{array}$} \\
\hline \multicolumn{4}{|c|}{\begin{tabular}{l|l|l|l} 
Tres o más áreas están implicadas en los & & & \\
programas
\end{tabular}} \\
\hline \multicolumn{4}{|c|}{ Dinámicas de trabajo y elaboración de materiales } \\
\hline \multicolumn{4}{|l|}{$\begin{array}{l}\text { La coordinación de los programas está } \\
\text { integrada en los órganos de coordinación del } \\
\text { centro }\end{array}$} \\
\hline \multicolumn{4}{|l|}{$\begin{array}{l}\text { Las actividades se adecuan a los distintos } \\
\text { niveles y edades del alumnado }\end{array}$} \\
\hline \multicolumn{4}{|l|}{$\begin{array}{l}\text { Se trabaja la competencia lingüística de } \\
\text { manera interdisciplinar }\end{array}$} \\
\hline \multicolumn{4}{|l|}{$\begin{array}{l}\text { Los programas se integran en el currículo de } \\
\text { las distintas áreas }\end{array}$} \\
\hline \multicolumn{4}{|l|}{$\begin{array}{l}\text { Existen dinámicas de trabajo colaborativo entre } \\
\text { el profesorado en la realización de actividades }\end{array}$} \\
\hline \multicolumn{4}{|l|}{$\begin{array}{l}\text { Se elaboran recursos y materiales didácticos } \\
\text { innovadores }\end{array}$} \\
\hline \multicolumn{4}{|l|}{$\begin{array}{l}\text { El alumnado realiza las actividades trabajando } \\
\text { cooperativamente }\end{array}$} \\
\hline \multicolumn{4}{|l|}{$\begin{array}{l}\text { El alumnado realiza tareas integradas o } \\
\text { proyectos de investigación en el aula para la } \\
\text { adquisición de la competencia lingüística. }\end{array}$} \\
\hline \multicolumn{4}{|l|}{$\begin{array}{l}\text { El alumnado utiliza las TIC y/o las redes } \\
\text { sociales en las actividades destinadas a la } \\
\text { mejora de la competencia en comunicación } \\
\text { lingüística }\end{array}$} \\
\hline \multicolumn{4}{|l|}{$\begin{array}{l}\text { El desarrollo de los programas ha generado en } \\
\text { el centro una dinámica de mayor actividad } \\
\text { cultural relacionada con el ámbito lingüístico }\end{array}$} \\
\hline \multicolumn{4}{|l|}{$\begin{array}{l}\text { El desarrollo de los programas ha reforzado el } \\
\text { papel de la biblioteca escolar como impulsora } \\
\text { de la mejora en el ámbito de la comunicación } \\
\text { lingüística }\end{array}$} \\
\hline \multicolumn{4}{|l|}{$\begin{array}{l}\text { Los proyectos y producciones del alumnado se } \\
\text { difunden al resto de la comunidad educativa }\end{array}$} \\
\hline $\begin{array}{l}\text { Las actividades de los programas son objeto de } \\
\text { evaluación por parte de las áreas participantes }\end{array}$ & & & \\
\hline
\end{tabular}




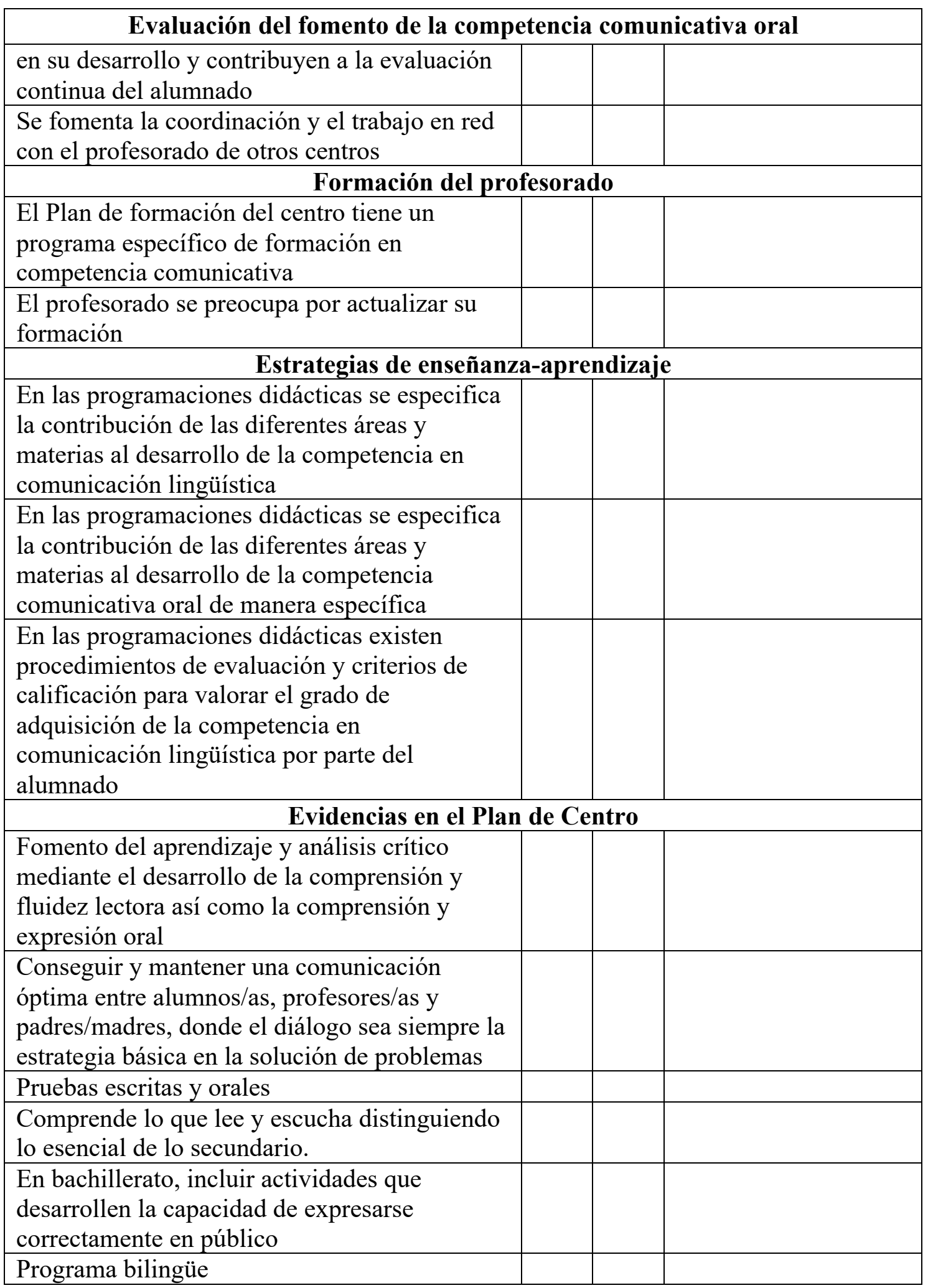

